\title{
COMPARISON OF MILK AND SERUM ENZYME-LINKED IMMUNOSORBENT ASSAYS ADJUSTED FOR TIME-RELATED FACTORS FOR THE DETECTION OF PARATUBERCULOSIS IN DAIRY CATTLE
}

\author{
Søren Saxmose Nielsen ${ }^{1}$, Jens Frederik Agger ${ }^{1}$ \\ ${ }^{1}$ Department of Animal Science and Animal Health, The Royal Veterinary and Agricultural University, \\ DK-1870 Frederiksberg C, Denmark
}

Paratuberculosis is a chronic infection caused by Mycobacterium avium subsp. paratuberculosis in cattle and other ruminants. An estimated high prevalence (Nielsen et al., 2000) and a huge production impact (e.g. Kudahl et al., 2001), renders action desirable. In-expensive tests with a high potential for automatisation are therefore wanted. In this aspect, enzyme-linked immunosorbent assays (ELISA) for detection of antibodies in milk and serum are relevant. Previous studies have revealed a poor correlation between the milk ELISA and the serum ELISA (Hardin and Thorne, 1996; Sweeney et al., 1994). However, these studies did not consider the fluctuations of antibody concentration in milk and serum across the lactation (Nielsen et al., unpublished data). The objective of this study was to compare the milk ELISA response with the serum ELISA response adjusted for timerelated factors.

Milk and serum samples were collected concomitantly from all lactating cows ( $n=3260)$ in 45 Danish dairy herds. The milk and serum samples were tested using a milk ELISA and a serum ELISA, respectively. The two ELISAs used on the same antigen. Information on days-in-milk (DIM), parity (P) and age-at-1st-calving (C1) was collected from the Danish Cattle Database.

Data were analysed using a multivariate mixed linear regression analysis. Logarithmic transformations of the optical densities (OD) for each of the ELISAs were used as the response variables. A model predicting the OD-value controlling for the age and calving related cow characteristics, i.e. DIM, P and C1 was developed for the ELISAs including information on weather a sample was tested in serum or milk ELISA. The contribution of ELISA-test for variance was thus assessed. Variability attributable to laboratory factors was also controlled for in the statistical analyses.

The final model included all factors DIM, P and C1. Laboratory variability was significant at the selected $95 \%$ level of confidence. However, the variability due to the ELISA test selected, was non-significant $(\mathrm{P}=0.24)$, suggesting there was no difference in weather the serum ELISA or the milk ELISA was used. These findings suggest that, given the ELISA result is corrected by cow characteristics, the predictive value of the ELISA should be the same whether used on milk or serum samples. It was therefore concluded that application of milk and serum ELISA for detection of paratuberculosis antibodies will give similar results presupposed the confounding effects of time is controlled for.

Hardin L.E., Thorne J.G., 1996. J. Am. Vet. Med. Assoc., 209: 120-122.

Kudahl A., Nielsen S.S., Sørensen J.T., in press. (these proceedings)

Nielsen S.S., Thamsborg S.M., Houe H., Bitsch V., 2000. Prev. Vet Med. 44, 1-7 (with Corrigendum in Prev. Vet. Med 46, 297).

Sweeney R.W., Whitlock R.H., Buckley C.L., Spencer P., 1994. Am. J. Vet. Res. 55: 905-909. 